\title{
Benefits, harms and cost-effectiveness of cancer screening in Australia: an overview of modelling estimates
}

\author{
a Cancer Council NSW, Sydney, Australia \\ b University of Melbourne, VIC, Australia \\ - University of Sydney, NSW, Australia \\ ${ }^{d}$ Griffith University, Gold Coast, QLD, Australia \\ e Monash University, Melbourne, VIC, Australia \\ † UNSW Sydney, Australia \\ g Corresponding author: jiebin.lew@nswcc.org.au
}

Jie-Bin Lewª, Eleonora Feletto ${ }^{a}$, Stephen Wade ${ }^{\mathrm{a}}$, Michael Caruana ${ }^{a}$, Yoon-Jung Kanga , Carolyn Nicksona,b, Kate T Simmsa, Pietro Procopio, Natalie Taylor ${ }^{\mathrm{a}}$, Joachim Worthingtona, David P Smitha,c,d,e and Karen Canfella,c,f

\section{Article history}

Publication date: July 2019

Citation: Lew J-B, Feletto E, Wade S,

Caruana M, Kang Y-J, Nickson C,

Simms KT, Procopio P, Taylor N, Worthington J, Smith DP, Canfell K. Benefits, harms and cost-effectiveness of cancer screening in Australia: an overview of modelling estimates. Public Health Res Pract. 2019;29(2):e2921913. https://doi.org/10.17061/phrp2921913

\section{Key points}

- The current population screening programs for cervical and colorectal cancers were found to be cost-effective and have a highly favourable benefit-toharm balance

- Further research should focus on deriving well-validated, locally applicable, quantitative estimates of benefits and harms (e.g. overdiagnosis and overtreatment) of the national breast cancer screening program and emerging screening approaches

\section{Abstract}

Introduction: There are three government-funded population-based screening programs in Australia - the national breast cancer screening program (BreastScreen Australia), the National Cervical Screening Program (NCSP), and the National Bowel Cancer Screening Program (NBCSP). Options for early detection of other cancers (e.g. hepatocellular carcinoma and melanoma) are under investigation. This study provides an overview of the health benefits, harms and cost-effectiveness of population-level breast, cervical and colorectal cancer screening, targeted-risk screening for lung cancer and Lynch syndrome, and prostate specific antigen (PSA) testing in Australia.

Methods: The study reviewed and, where possible, updated the estimated health benefits, harms and cost-effectiveness of screening approaches from modelling studies for four cancer types, PSA testing and Lynch syndrome testing in Australia. Costs are presented in 2018 Australian dollars.

Results: The renewed NCSP (for women not HPV-vaccinated) and the NBCSP were estimated to be cost-effective versus no screening; the cost-effectiveness ratio (CER) was \$16 632 per life-year saved (LYS) for the NCSP, and \$3380/ LYS for the NBCSP. BreastScreen Australia was predicted to have a CER of \$40 279/LYS-\$65 065/LYS. In 2017, the NCSP transitioned to 5-yearly primary HPV testing with partial genotyping for HPV types 16 and 18 for women aged 25-74 years. Alongside vaccination, this change is predicted to prevent a further 587 cervical cancer deaths in 2018-2035, and have a favourable benefit-to-harm balance versus prior practice (biennial cytology testing for women aged 18-69 years). On average, the NBCSP (biennial screening using an immunochemical faecal occult blood test for people aged 50-74 years) is estimated to prevent 2519 colorectal cancer deaths and result in 350 colonoscopy-related adverse events annually. 
The inaccuracy of PSA testing as a screening tool impedes the capacity to conduct meaningful cost-effectiveness analyses at a population level, based on current evidence. Three annual low-dose computed tomography screens for lung cancer using the US National Lung Screening Trial selection criteria would not be cost-effective in Australia. A comprehensive cost-effectiveness evaluation of systematic proband testing, cascade testing and subsequent surveillance for Lynch syndrome in Australia is currently underway.

Conclusions: Current evidence supports a favourable cost-effectiveness and benefit-to-harm balance for the NCSP and NBCSP. An updated costeffectiveness and benefits-to-harms analysis for BreastScreen Australia is required. Carefully founded quantitative estimates of health benefits, harms and cost-effectiveness provide an important aid to policy decision making, and form the basis for developing decision aids to guide individual screening decisions. Opportunities exist for lung cancer screening, systematic Lynch syndrome testing and informed decision making about PSA testing. However, more evidence is required on risk assessment, targeting of screening tests, optimal referral pathways, managing potential harms and delivering services in a cost-effective framework.

\section{Overview}

Cancer screening, as underpinned by World Health Organization $(\mathrm{WHO})$ screening principles ${ }^{1}$, aims to detect cancer and its warning signs early in asymptomatic people. For cancers with a recognisable latent (i.e. a precancerous condition) or an early stage, screening could reduce cancer incidence and mortality by detecting and managing precancerous conditions or a cancer.

Screening can also lead to potential harms such as false-positive screening results, adverse events and overdiagnosis/overtreatment of cancer that would not have become symptomatic if undetected. These harms can cause distress to individuals, as well as inefficient use of healthcare resources.

Cost-effectiveness of cancer screening is critical when planning for a population-based program, particularly if it is to be government funded. In Australia, an indicative willingness-to-pay (WTP) threshold of \$30 000-50 000 per life-year saved (LYS) or quality-adjusted life-year saved (QALYS) is used to assess the cost-effectiveness of cancer screening and other prevention strategies. ${ }^{2-4}$ Advocates for evidence-based change should acknowledge this threshold.

The triad of benefits, harms and costs is a key element of the Australian Population Based Screening Framework $(\text { Box } 1)^{5}$, adapted from the classic 1968 WHO screening principles. ${ }^{1}$ The benefits-and-harms balance (e.g. number-needed-to-screen [NNS] and/ or number-needed-to-treat [NNT] to prevent a cancer or cancer death), and costs-to-benefits ratio (i.e. costeffectiveness ratio [CER] - cost per LYS or cost per QALYS) are summary measures for this triad (Figure 1). The clinical procedures for the implementation of screening, diagnosis and treatments vary by cancer type; and it is acknowledged that an individual's level of psychosocial impact might vary widely even for the same procedures in the same populations. This should be noted when comparing the benefits-and-harms balance for different cancer types.

Box 1. World Health Organization screening criteria, as summarised for the Australian Population Based Screening Framework

\section{Condition}

- The condition should be an important health problem

- There should be a recognisable latent or early stage

- The natural history of the disease, including development from latent to declared disease, should be adequately understood

\section{Test}

- There should be a suitable test or examination

- The test should be acceptable to the population

\section{Treatment}

- There should be an accepted treatment for patients with recognised disease

\section{Screening program}

- There should be an agreed policy on who to treat as patients

- Facilities for diagnosis and treatment should be available

- The cost for case-finding (including diagnosis and treatment of patients diagnosed) should be economically balanced in relation to expenditure on medical care as a whole

- Case-finding should be a continuing process and not a 'once and for all' project.

Source: Wilson and Jungner, $1968^{1}$ 
Figure 1. Benefits, harms and costs of cancer screening and ratios used to summarise these key parameters

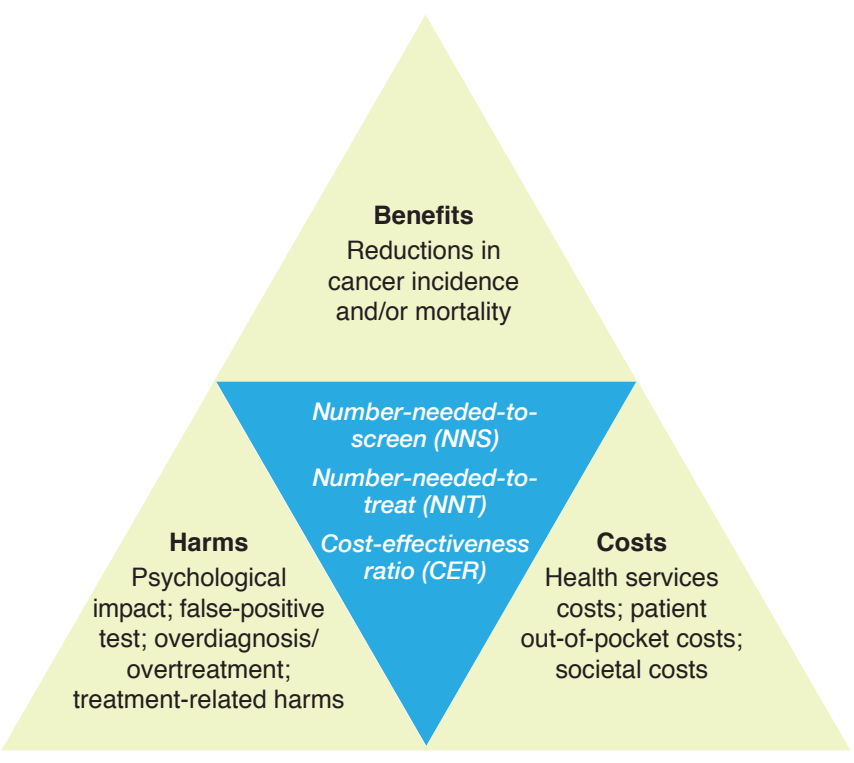

Currently, there are three Government-funded population-based cancer screening programs in Australia - the national breast cancer screening program (BreastScreen Australia), the National Cervical Screening Program (NCSP) and the National Bowel Cancer Screening Program (NBCSP). This review aims to summarise the available quantitative estimates of the benefits, harms and cost-effectiveness of the three organised screening programs, potential screening approaches for two of the most common causes of cancer deaths (prostate and lung cancer; see Appendix 1, available from: figshare.com/articles/ Benefits_harms_and_cost-effectiveness_of_cancer_ screening_in_Australia_an_overview_of_modelling_ estimates_online_appendix」/8426531), and systematic testing for Lynch syndrome in Australia. We focused on and, where possible, updated our own estimates specifically derived for Australia using a formal and comprehensive natural history-based modelling methodology. We did not explicitly review estimates that were directly adapted from overseas data, although we refer to such estimates in some cases (particularly for breast screening) and acknowledge that they can be useful in the absence of other locally validated information. We discuss the key issues, particularly costeffectiveness, and provide a verdict, including research prioritisation, for each cancer type and Lynch syndrome based on the current evidence.

\section{Breast cancer}

As described in this issue of the journal by Nickson et al, BreastScreen Australia was phased in from 1991, providing free biennial mammographic screening. ${ }^{6}$ Among women in the target age range (currently 50-74 years), around 55\% participate in the program, $49 \%$ of population-level invasive breast cancers and $73 \%$ of ductal carcinoma in situ (DCIS) cases are screen-detected, and mortality is reduced by around $50 \%$ for participants and $28 \%$ across the population. ${ }^{7,8}$ An independent evaluation published 10 years ago concluded that BreastScreen Australia had reduced mortality from breast cancer in the target age group (women aged 50-69 years) by approximately 21-28\%. ${ }^{9}$

Additionally, early detection through BreastScreen appears to reduce the intensity of treatment, even after accounting for overdiagnosis. ${ }^{10}$ In terms of harms, some proportion of screen-detected cancers are likely to be overdiagnosed. Derived from the findings of UK and European reviews, approximately eight breast cancers were estimated to be overdiagnosed for every 1000 women aged 50-74 years who are screened biennially in Australia ${ }^{11}$, although estimates are highly uncertain. False-positive screens and interval cancers should be minimised where possible. All DCIS are currently treated, but an estimated $25-60 \%$ of DCIS would not progress to invasive breast cancer. ${ }^{12}$ Outside BreastScreen, Family Cancer Centres and Medicare items for magnetic resonance imaging and genetic testing provide increased surveillance of high-risk women.

Updated, comprehensive Australian benefit and harm estimates are needed. Single-cohort Markov modelling in the 2009 BreastScreen Australia evaluation estimated that the cost-effectiveness of the BreastScreen program (versus no screening) for women aged 50-69 years was \$38 302/LYS over 20 years, and \$23 713 over 40 years (equivalent to $\$ 65$ 065/LYS and $\$ 40$ 279/LYS respectively in 2018 value; Table 1) ${ }^{9}$; cost-effectiveness was estimated to decline for women older than 70 years. ${ }^{13}$ Testing for germline mutations for breast cancer patients appears more cost-effective when extended to unaffected family members (incremental CER: \$9500/QALY gained, versus no testing). ${ }^{14}$ With increasing interest in targeted-risk screening, future updated clinical and cost-effectiveness models should draw from methods applied in other settings ${ }^{15,16}$, and incorporate clinical, cost and quality-of-life measures for treatment intensity, overdiagnosis, false-positive screens and interval cancers. Nickson et al. ${ }^{6}$ further explore opportunities in risk-stratified screening, with a recommended framework for reviewing risk-based protocols.

Verdict: An updated and more comprehensive analysis of cost-effectiveness and benefit-to-harm balance of BreastScreen Australia is required. There may be opportunities to improve clinical and costeffectiveness outcomes through more personalised approaches to breast screening. 


\section{Cervical cancer}

The NCSP was established in 1991. Until 2017, it provided biennial screening using the Papanicolaou test for women aged 18-69 years ('pre-renewal NCSP'). The age-standardised rate of cervical cancer mortality has halved over the period of 1991-2018, from 3.8 to 1.8/100 000 women. ${ }^{17-19}$ The National HPV Vaccination Program was introduced in 2007, initially providing quadrivalent (HPV4) human papillomavirus (HPV) vaccine for girls aged 12-13 years, with a 2-year catchup program for women up to 26 years of age. ${ }^{20}$ The program was expanded in 2013 to include boys aged 12-13 years. ${ }^{20}$ The HPV4 vaccine protects against HPV types 16 and 18, which are responsible for more than $70 \%$ of cervical cancers (as well as HPV types 6 and 11, which are implicated in almost all anogenital warts). ${ }^{21}$ In 2017, the nationwide three-dose coverage rate was more than $76 \%$ among eligible females. ${ }^{20} \mathrm{~A}$ considerable decline in high-grade cervical abnormalities has been observed in young Australian females. ${ }^{22}$
Using Policy 1-Cervix, a well-validated dynamic multicohort modelling platform ${ }^{23-25}$, the pre-renewal NCSP was estimated to prevent 2579 cervical cancers and 1185 cervical cancer deaths per year (in the absence of vaccination), with a benefits-and-harms balance of 2085 NNS per cervical cancer death prevented, and a CER of $\$ 23$ 244/LYS in unvaccinated cohorts versus no screening (Table 1). ${ }^{25}$

From December 2017, the NCSP switched from biennial cytology for women aged 20-69 years to 5-yearly HPV testing with partial genotyping for HPV types 16/18 for women aged 25-74 years ('renewed NCSP').. ${ }^{26,27}$ The renewed NCSP is predicted to be more effective than the pre-renewal NCSP. Alongside vaccination, the renewed NCSP was estimated to prevent an additional 2006 cases and 587 deaths over the period 2018-2035. ${ }^{23}$ Numbers provided in Table 1 show that the renewed NCSP would avert more cancer cases and deaths, requires fewer screening tests in a woman's lifetime, is less costly, and has a more favourable benefit-to-harm balance when compared with the pre-renewal NCSP.

Table 1. Health benefits, benefit-to-harm balance and cost-effectiveness of cancer screening in 2020 in Australia

\begin{tabular}{|c|c|c|c|c|c|c|c|c|}
\hline \multirow[t]{2}{*}{$\begin{array}{l}\text { Cancer } \\
\text { type }\end{array}$} & \multirow[t]{2}{*}{$\begin{array}{l}\text { Screening } \\
\text { strategy }\end{array}$} & \multirow[t]{2}{*}{ Comparator } & \multicolumn{4}{|c|}{$\begin{array}{l}\text { Estimated outcomes per annum } \\
\text { (assuming the projected } 2020 \text { Australian population) }{ }^{32}\end{array}$} & \multirow{2}{*}{$\begin{array}{l}\text { NNS and } \\
\text { NNT per } \\
\text { cancer } \\
\text { death } \\
\text { prevented }^{b}\end{array}$} & \multirow{2}{*}{$\begin{array}{c}\text { CER } \\
(\$ / L Y S, \text { in } \\
2018 \text { AUD) }\end{array}$} \\
\hline & & & $\begin{array}{l}\text { Number } \\
\text { of people } \\
\text { screened }\end{array}$ & $\begin{array}{c}\text { Number of } \\
\text { diagnostic } \\
\text { assessments }\end{array}$ & $\begin{array}{l}\text { Number } \\
\text { of cancers } \\
\text { (cx) and } \\
\text { deaths ( } \mathrm{dx} \text { ) } \\
\text { prevented }\end{array}$ & $\begin{array}{c}\text { Cost } \\
\text { (million, } \\
2018 \text { AUD) }\end{array}$ & & \\
\hline \multirow[t]{5}{*}{ Cervical 23,25} & $\begin{array}{l}\text { Pre-renewal } \\
\text { NCSP, not } \\
\text { vaccinated }^{d}\end{array}$ & No screening & 2.47 million & $\begin{array}{l}91083 \\
\text { COLPs }\end{array}$ & $\begin{array}{l}2579(\mathrm{cx}) \\
1185(\mathrm{dx})\end{array}$ & $\$ 223^{e}$ & $\begin{array}{l}2085 \text { (NNS) } \\
77 \text { (NNT) }\end{array}$ & $\$ 23244^{f}$ \\
\hline & $\begin{array}{l}\text { Pre-renewal } \\
\text { NCSP, HPV4 } \\
\text { vaccinated }^{d, g}\end{array}$ & $\begin{array}{l}\text { No } \\
\text { screening, } \\
\text { HPV4 } \\
\text { vaccinated }\end{array}$ & 2.45 million & $\begin{array}{l}56695 \\
\text { COLPs }\end{array}$ & $\begin{array}{l}561(c x) \\
276(d x)\end{array}$ & $\$ 195^{e}$ & $\begin{array}{l}8872 \text { (NNS) } \\
216 \text { (NNT) }\end{array}$ & $\$ 102687^{\dagger}$ \\
\hline & $\begin{array}{l}\text { (Current } \\
\text { practice) } \\
\text { Renewed } \\
\text { NCSP, not } \\
\text { vaccinated }^{d}\end{array}$ & No screening & 1.53 million & $\begin{array}{l}121575 \\
\text { COLPs }\end{array}$ & $\begin{array}{l}2854(c x) \\
1279(d x)\end{array}$ & $\$ 214^{e}$ & $\begin{array}{l}1199 \text { (NNS) } \\
95 \text { (NNT) }\end{array}$ & $\$ 16632^{f}$ \\
\hline & $\begin{array}{l}\text { (Current } \\
\text { practice) } \\
\text { Renewed } \\
\text { NCSP, HPV4 } \\
\text { vaccinated }\end{array}$ & $\begin{array}{l}\text { No } \\
\text { screening, } \\
\text { HPV4 } \\
\text { vaccinated }^{f}\end{array}$ & 1.42 million & $\begin{array}{l}46630 \\
\text { COLPs }\end{array}$ & $\begin{array}{l}648(c x) \\
302(d x)\end{array}$ & $\$ 156^{e}$ & $\begin{array}{c}4698 \text { (NNS), } \\
154 \text { (NNT) }\end{array}$ & $\$ 66893^{\dagger}$ \\
\hline & $\begin{array}{l}\text { (Current } \\
\text { practice) } \\
\text { Renewed } \\
\text { NCSP, HPV9 } \\
\text { vaccinated }^{\mathrm{d}, \mathrm{g}}\end{array}$ & $\begin{array}{l}\text { No } \\
\text { screening, } \\
\text { HPV9 } \\
\text { vaccinated }\end{array}$ & 1.34 million & $\begin{array}{l}22175 \\
\text { COLPs }\end{array}$ & $\begin{array}{l}333(c x) \\
153(d x)\end{array}$ & $\$ 126^{e}$ & $\begin{array}{l}8776 \text { (NNS) } \\
145 \text { (NNT) }\end{array}$ & $\$ 102897^{\dagger}$ \\
\hline
\end{tabular}




\begin{tabular}{|c|c|c|c|c|c|c|c|c|}
\hline \multirow[t]{2}{*}{$\begin{array}{l}\text { Cancer } \\
\text { type }\end{array}$} & \multirow[t]{2}{*}{$\begin{array}{l}\text { Screening } \\
\text { strategy }\end{array}$} & \multirow[t]{2}{*}{ Comparator } & \multicolumn{4}{|c|}{$\begin{array}{l}\text { Estimated outcomes per annum } \\
\text { (assuming the projected } 2020 \text { Australian population) }{ }^{32}\end{array}$} & \multirow{2}{*}{$\begin{array}{l}\text { NNS and } \\
\text { NNT per } \\
\text { cancer } \\
\text { death } \\
\text { prevented }^{b}\end{array}$} & \multirow{2}{*}{$\begin{array}{c}\text { CER } \\
\text { (\$/LYS, in } \\
2018 \text { AUD) }{ }^{c}\end{array}$} \\
\hline & & & $\begin{array}{l}\text { Number } \\
\text { of people } \\
\text { screened }\end{array}$ & $\begin{array}{c}\text { Number of } \\
\text { diagnostic } \\
\text { assessments }\end{array}$ & $\begin{array}{l}\text { Number } \\
\text { of cancers } \\
\text { (cx) and } \\
\text { deaths (dx) } \\
\text { prevented }\end{array}$ & $\begin{array}{c}\text { Cost } \\
\text { (million, } \\
2018 \text { AUD) }\end{array}$ & & \\
\hline Breast & $\begin{array}{l}\text { (Current } \\
\text { practice) } \\
\text { Biennial } \\
\text { mammography } \\
\text { screening for } \\
\text { women aged } \\
50-74 \text { years }\end{array}$ & No screening & $\begin{array}{c}886270 \\
(2015-2016) \\
h, 33\end{array}$ & $\begin{array}{c}41763 \\
\text { assessments } \\
(\text { in 2016) }\end{array}$ & $580(d x)^{h}$ & $\$ 316^{\mathrm{h}, 33}$ & $\begin{array}{c}1528 \text { (NNS) } \\
62 \text { (NNT) }\end{array}$ & $\begin{array}{c}\$ 40279 / L Y S \\
(>40 \text { years) } \\
\$ 65065 \\
(>20 \text { years) })^{h, 9}\end{array}$ \\
\hline \multirow[t]{3}{*}{ Colorectal $^{34}$} & $\begin{array}{l}\text { (Current } \\
\text { practice) } \\
\text { Biennial iFOBT } \\
\text { screening for } \\
\text { people aged } \\
50-74 \text { years }\end{array}$ & No screening & 1.44 million & $\begin{array}{l}114015 \\
\text { COLs }\end{array}$ & $\begin{array}{l}4308(c x) \\
2519(d x)^{i}\end{array}$ & $\$ 1410^{j}$ & $\begin{array}{l}572 \text { (NNS), } \\
42 \text { (NNT) }\end{array}$ & $\$ 3380^{\dagger}$ \\
\hline & $\begin{array}{l}\text { Biennial iFOBT } \\
\text { screening for } \\
\text { people aged } \\
45-74 \text { years }\end{array}$ & No screening & 1.80 million & $\begin{array}{l}133595 \\
\text { COLs }\end{array}$ & $\begin{array}{l}4826(c x) \\
2801(d x)\end{array}$ & $\$ 1450^{i}$ & $\begin{array}{l}644 \text { (NNS) } \\
48 \text { (NNT) }\end{array}$ & $\$ 6136^{\dagger}$ \\
\hline & & $\begin{array}{l}\text { (Current } \\
\text { practice) } \\
\text { Biennial } \\
\text { FOBT } \\
\text { screening for } \\
\text { people aged } \\
\text { 50-74 years }\end{array}$ & 363642 & 19579 COLs & $\begin{array}{l}517(c x) \\
282(d x)\end{array}$ & $\$ 38^{j}$ & $\begin{array}{l}1290 \text { (NNS) } \\
69 \text { (NNT) }\end{array}$ & $\begin{array}{c}\text { Incremental } \\
\text { CER: } \\
\$ 19126^{\dagger}\end{array}$ \\
\hline Lung & $\begin{array}{l}\text { Three rounds } \\
\text { of annual LDCT } \\
\text { screening } \\
\text { for high-risk } \\
\text { smokers aged } \\
55-74 \text { years }^{k}\end{array}$ & No screening & $\mathrm{N} / \mathrm{A}$ & N/A & $\mathrm{N} / \mathrm{A}$ & $\mathrm{N} / \mathrm{A}$ & $N / A$ & $\$ 154776^{\mathrm{f}, 35}$ \\
\hline
\end{tabular}

$\mathrm{AUD}=$ Australian dollars; $\mathrm{CER}=$ cost-effectiveness ratio; $\mathrm{COL}=$ colonoscopy; $\mathrm{COLP}=$ colposcopy; HPV = human papillomavirus;

HPV4 = quadrivalent HPV vaccine; HPV9 = nonavalent HPV vaccine; iFOBT = immunochemical faecal occult blood test; LDCT = low-dose computed tomography; LYS = life-year saved; N/A = not available; NCSP = National Cervical Screening Program; NNS = number-needed-toscreen; NNT = number-needed-to-treat

a Inflated to 2018 value $^{36}$

b The NNS and NNT per cancer death prevented were calculated by dividing the number of people screened and number of diagnostic assessments, respectively, by the number of cancer deaths prevented per annum

c The screening program participation assumed for the cost-effectiveness analyses were $53 \%$ (2-year participation) for pre-renewal NCSP $25,37,86 \%$ (5-year participation) for renewed NCSP, 55\% (2-year participation) for biennial mammography screening ${ }^{33}, \sim 40 \%$ (2-year participation) for biennial iFOBT screening ${ }^{34,38}$, and $95 \%$ for annual LDCT screening ${ }^{35}$

d 'Pre-renewal NCSP' refers to biennial cytology for women aged 18-69 years; 'renewed-NCSP' refers to 5-yearly HPV testing with partial genotyping for HPV types 16/18 for women aged 25-74 years

Including costs associated with cytology and/or HPV testing, colposcopy, treatment for precancers and cervical cancers

Calculated using lifetime cost and life-years discounted at $5 \%$ per annum

g This scenario assumed the cohort was offered HPV vaccine at 12 years of age in 2019; it takes into account the herd immunity of the National HPV Vaccination Program, which was introduced in $2007^{20}$

n See Appendix 1 for more details (available from: figshare.com/articles/Benefits_harms_and_cost-effectiveness_of_cancer_screening_in_ Australia_an_overview_of_modelling_estimates_online_appendix_8426531)

The estimates were calculated from outcomes predicted for a single cohort with full exposure to the biennial program. ${ }^{34}$ The estimates would be 4619 colorectal cancers and 2719 colorectal cancer deaths prevented per annum if the average of the total number of cases and deaths prevented predicted for 2020-2040 was used 39

Including the cost of iFOBT screening, colonoscopy (to follow up positive iFOBT result and downstream surveillance), polypectomy and colorectal cancer treatment

k People who had a 30 pack-year smoking history, still smoked or had quit within 15 years prior (based on selection and implementation criteria of the National Lung Screening Trial in the US) $)^{40}$ 
In 2018, Australia adopted a nonavalent HPV (HPV9) vaccine to replace HPV4 vaccine. ${ }^{28}$ The HPV9 vaccine protects against nine types of HPV, which are responsible for more than $90 \%$ of cervical cancers. ${ }^{29}$ Considering the impact of both vaccination and screening, the agestandardised rate of cervical cancer was estimated to decrease to less than 6/100 000 women by around 2020, and to less than 4/100 000 women by 2035; at this point it would be considered eliminated as a public health problem. ${ }^{23,30}$ Once this very low-level rate is achieved, even under the assumption that cohorts offered HPV9 never undergo screening in their lifetime, the overall cervical cancer incidence rate in Australia is predicted to remain below this threshold for elimination. ${ }^{23}$ Previous studies have found that 5-yearly primary HPV testing for women aged 25-74 years might not be cost-effective for women vaccinated with HPV9 vaccine, and that two screens in a woman's lifetime was the most cost-effective approach for cohorts offered this vaccine (Table 1). ${ }^{31}$ It should be noted that when young next-generation vaccinated cohorts mature and enter the renewed NCSP will become less cost-effective (as shown in Table 1), and in the future a reduction in the number of lifetime screens might be considered. ${ }^{31}$

Verdict: Cervical cancer screening in Australia has been a major success; evidence shows the change to the renewed NCSP has the potential to improve on that success, and, along with HPV vaccination, is expected to further reduce disease burden over the coming decades.

\section{Colorectal cancer}

As reported by Ee and St John in this issue, the NBCSP, introduced incrementally from 2006, has the potential to have a major impact in Australia and save many thousands of lives. ${ }^{41}$ From 2019, the program provides biennial screening using immunochemical faecal occult blood testing (iFOBT) to people aged $50-74$ years. ${ }^{42}$ Using a comprehensively calibrated microsimulation model, Policy1-Bowel, the NBCSP was estimated to prevent 97000 colorectal cancers and 57100 colorectal cancer deaths in 2020-2040 at the observed 40\% participation rate, equivalent to more than 4000 colorectal cancers and more than 2500 colorectal cancer deaths prevented annually (Table 1)..$^{39}$ If the NBCSP participation increased to $60 \%$ by 2020, an additional 40400 cancers and 24700 deaths could be prevented in 2020-2040. ${ }^{39}$

The annual expenditure for cancer treatment was estimated to increase from $\$ 858$ million in 2006 to approximately $\$ 1$ billion by 2010 and to approximately $\$ 2$ billion by 2040 in the absence of screening. ${ }^{39}$ The NBCSP is expected to result in a lower annual expenditure (including the cost of providing iFOBT screening, colonoscopy assessments to follow up positive iFOBT results and for further surveillance, and colorectal cancer treatment) than no screening from 2029 onwards, after a transient increase in 2006-2028. ${ }^{39}$ The fully implemented NBCSP is predicted to be very cost-effective
(CER: \$3380/LYS) and have a favourable benefit-toharm balance, of 572 NNS per colorectal cancer death prevented, compared with no screening (Table 1). ${ }^{39}$

A recent comparative evaluation concluded that the current NBCSP was estimated to have the most favourable cost-effectiveness and benefits-to-harms ratios when compared with alternative screening technologies. ${ }^{38}$ The currently targeted screening age range, 50-74 years, was found to be the optimal age range for biennial iFOBT screening when compared with alternative age ranges. ${ }^{34}$ Lowering the NBCSP starting age to 45 years was predicted to be potentially cost-effective (incremental CER: $\$ 19$ 126/LYS) but have a less favourable benefitto-harm balance (more than 1200 NNS per additional colorectal cancer death prevented) than screening for the currently targeted 50-74 years age group (Table 1). ${ }^{34}$

In line with international evidence, increasing colorectal cancer incidence has been found in people aged younger than 50 years. ${ }^{43}$ The optimal NBCSP screening starting age may need to be re-evaluated for these younger birth cohorts if this trend in colorectal cancer incidence continues.

Verdict: The NBCSP is extremely effective and costeffective. Evidence on extending the age cohort and assessing new technologies should be reviewed and assessed as it becomes available.

\section{Prostate cancer}

Although there is no screening program for prostate cancer, prostate specific antigen (PSA) testing is widely used to detect prostate abnormalities in asymptomatic men in Australia. Approximately 1.5 million PSA tests were subsidised by Medicare in 2017. ${ }^{44}$ Outcomes from international trials on PSA testing have been inconsistent. The European Randomised Study of Screening for Prostate Cancer reported a $21 \%$ reduction in prostate cancer mortality in men aged $55-69$ years who underwent PSA testing every 4 years (2 years for participants in Sweden), with a PSA threshold for biopsy referral of $3 \mathrm{ng} /$ $\mathrm{mL}$, over 11 years of follow-up. ${ }^{45}$ The US Prostate, Lung, Colorectal and Ovarian Screening Trial found no evidence of a mortality benefit for organised annual PSA screening, with a PSA threshold for biopsy referral of $4 \mathrm{ng} / \mathrm{mL}$, compared with the control arm after 13 years of followup; however, this result is known to be influenced by opportunistic screening in the control arm. ${ }^{46}$ A systematic review and meta-analysis used data from five trials on PSA testing and concluded with low certainty that PSA testing may have no effect on prostate-specific mortality. ${ }^{47}$

After considering the international evidence, clinical practice guidelines for PSA testing and early management of screen-detected prostate cancer in Australia were published in 2016. ${ }^{48}$ These guidelines recommend that 'men at average risk of prostate cancer, who have been informed of the benefits and harms of testing and who decide to undergo regular testing for prostate cancer, are offered PSA testing every 2 years 
from age 50 to age 69, and offered further investigation if total PSA is greater than $3.0 \mathrm{ng} / \mathrm{mL}^{\prime} .{ }^{48}$

An Australian study used a single-cohort Markov model to evaluate the cost-effectiveness of 4-yearly PSA testing versus no testing for men at average risk, high risk (two times the average risk) and very high risk (five times the average risk) for prostate cancer. ${ }^{49}$ This evaluation found that annual PSA testing may be cost-effective for very high-risk men (CER: \$22 938/QALYS, equivalent to CER \$28 140/QALYS in 2018 value) but not for averagerisk or high-risk men.

An Australian model, Policy1-Prostate, is in the final stages of development for the ongoing epidemiologic and economic evaluation of changes in the detection, management and treatment of prostate cancer, and of the interactive effects of these changes on outcomes (including cancer incidence, mortality and treatmentrelated morbidity) and costs..$^{50}$

Verdict: On current evidence, the inaccuracy of PSA testing as a screening tool impedes the capacity to conduct meaningful cost-effectiveness analyses at a population level. Morbidity associated with treatment continues to be a problem. More research is needed on strategies for identifying men at increased risk of prostate cancer.

\section{Lung cancer}

As reported by Weber et al in this issue, lung cancer screening by low-dose computed tomography (LDCT) could see major reductions in the lung cancer burden in Australia. ${ }^{51}$ However, a regimen that would deliver a balance of benefits, harms and cost-effectiveness in Australia has not been identified. ${ }^{52}$

The US National Lung Screening Trial compared three annual LDCT lung screens to chest $X$-ray for smokers aged 55-75 years, who had a 30 pack-year history (e.g. smoking 20 cigarettes a day for 30 years) and still smoked or had quit within 15 years prior, and found a relative $20 \%$ reduction in cancer mortality. ${ }^{35,53} \mathrm{~A}$ recent cost-effectiveness analysis of this trial using Australian costs estimated a CER of \$154 776/LYS compared with usual care, far exceeding the indicative WTP threshold in Australia (Table 1). ${ }^{35}$ A review of this and other trials has shown considerable variation in outcomes relevant to the balance of benefits, harms and cost-effectiveness, such as screening rates, false-positive rates and lung cancer detection rates, all of which are sensitive to the screening regimen and target population. ${ }^{54}$

The recently commenced International Lung Screen Trial in Australia and Canada ${ }^{55}$ will provide essential information on screening a high-risk Australian cohort, and aid in identifying an acceptable cost-effective screening program in Australia.

Verdict: Lung cancer screening may only be supported with greater evidence on the cost-effective screening of a high-risk Australian cohort. The high disease burden of lung cancer suggests lung cancer screening is among the most important unresolved screening issues.

\section{Lynch syndrome}

As explored in the article by Taylor et al in this issue ${ }^{56}$, Lynch syndrome is associated with earlier onset of several cancers, predominantly colorectal and endometrial cancers, and presents opportunities and challenges in cancer screening.

In Australia, there has been a call for systematic testing to identify Lynch syndrome carriers in incident cancer cases (i.e. proband testing) and offering cascade genetic testing to at-risk family members (i.e. cascade testing). This has been reflected in a recent Medical Services Advisory Committee (MSAC) application to subsidise germline gene panel testing for inheritable mutations associated with colorectal and endometrial cancers. ${ }^{57} \mathrm{~A}$ range of cancer risk management options, such as colonoscopic surveillance and prophylaxis, could be offered to confirmed Lynch syndrome carriers to reduce the risk of associated morbidity and mortality.

To date, no assessment of systematic testing for Lynch syndrome considering all relevant testing and triage options, cascade testing, subsequent surveillance, and sequelae, has been published for Australia. A 2006 evaluation assessed a strategy assuming cascade testing was offered in a family cancer clinic setting; those with confirmed mutations were offered intensive surveillance and risk-reducing surgery/surgeries for multiple Lynch syndrome-related cancers. ${ }^{58}$ This cascade testing strategy was estimated to cost less than $\$ 13000$ (net) for eight colorectal cancer-free years per person than no cascade testing. ${ }^{58}$ The study considered an average lifetime treatment cost for each colorectal cancer detected ${ }^{58}$; colorectal cancer treatment costs have increased substantially over the past two decades. ${ }^{59}$

A recent economic evaluation to support the aforementioned MSAC application assessed firstly the cost-effectiveness of proband testing, then secondly, with the addition of a cascade testing strategy. ${ }^{57}$ The strategy assumed some proportion of the proband's relatives (between 0 and 100\%) participated in active familial colonoscopic surveillance before the genetic testing. Only individuals with a positive result would thereafter continue to participate in or take up surveillance. Cascade testing was estimated to be cost-effective in most scenarios and cost-saving if $60-97 \%$ of probands relatives participated in surveillance before genetic testing was offered. ${ }^{57}$ Potential downstream costs or savings associated with surveillance, prophylaxis and cancer treatments were not considered. ${ }^{57}$ The cost per single proband identified was $\$ 9762 .{ }^{57}$

Cenin and colleagues evaluated and compared the cost and benefit of offering Lynch syndrome testing in cases of colorectal cancer diagnosed at ages $<50$, $<60$ or $<70$ years, and at any age. ${ }^{60}$ Findings indicated that Lynch syndrome testing in colorectal cancer cases diagnosed at $<70$ years would detect more Lynch syndrome cases at a reasonable cost; testing in older ages would not identify more Lynch syndrome cases at a much higher cost. ${ }^{60}$ 
A comprehensive cost-effectiveness evaluation of systematic proband testing, cascade testing and subsequent surveillance for Lynch syndrome in Australia is currently underway. ${ }^{61}$

Verdict: Comprehensive evidence on the risks, benefits and cost-effectiveness of Lynch syndrome screening is required. Although the pace of genomics technology presents opportunities, it also poses challenges in health economics as settings for evaluation evolve rapidly.

\section{Conclusion}

Research to identify optimal approaches to populationbased screening for different cancer types in Australia shows much promise, based on analyses of benefits harms, and cost-effectiveness. The evidence to date strongly supports the cost-effectiveness of two of the organised cancer screening programs for averagerisk Australians - NCSP and NBCSP. However, these population-level estimates do not account for differing risk profiles or lower rates of screening uptake in certain population subgroups. Extending the research agenda to better quantify and understand the benefits, harms and cost-effectiveness of cancer screening by risk group and for population subgroups, such as Aboriginal and Torres Strait Islander Australians, are needed.

In the case of BreastScreen, although a 10-year-old Australian review showed a mortality benefit, renewed and ongoing efforts to estimate the benefits, harms and costeffectiveness of the program, considering the potential for overdiagnosis and overtreatment, are warranted.

Optimising PSA testing by reconsidering the testing age range, interval, test-positive threshold and surveillance strategies should be considered high-priority research; again, the potential for overdiagnosis and overtreatment, as well as mortality benefits, need to be considered.

Criteria for assessing cost-effectiveness of Lynch syndrome testing may change rapidly as the technology evolves. Accordingly, researchers and policy analysts will require increasingly sophisticated models for evaluating the evidence. By contrast, technologies under review for lung cancer screening are well established. Although current evidence shows that using LDCT screening for high-risk smokers is not likely to be cost-effective in Australia, the cost-effectiveness of such a screening strategy could improve if evidence strengthens on screening eligibility criteria, the costs of LDCT reduce and/or the costs of lung cancer treatment increase. Future evaluations should consider factors such as alternative screening eligibility criteria and the diagnostic test referral threshold. As lung cancer is the most common cause of cancer deaths in Australia, systematic and effective early detection of lung cancer could be a game changer in cancer mortality reduction.
Opportunities for systematic approaches to the early detection of cancer will continue to emerge, and should be continually researched and evaluated to ensure they deliver more benefits than harms and are cost-effective.

\section{Acknowledgements}

$\mathrm{KC}$ received National Health and Medical Research Council Career Development Fellowships (APP1007994 and APP1082989). NT has a fellowship from Cancer Institute NSW (CDF005).

\section{Peer review and provenance}

Externally peer reviewed, commissioned.

\section{Competing interests}

MC was an Investigor on a Prostate Cancer Foundation of Australia-funded grant 'Testing and treatment for prostate cancer in Australia: epidemiology and modelling'. KC, MC and $\mathrm{Y}$-JK were Investigators on the National Health and Medical Research Council-funded project 'Effectiveness and cost-effectiveness of systematic screening for Lynch Syndrome in Australia'. MC is an Investigator and KC is co-Principal Investigator on an investigator-initiated trial of cytology and primary HPV screening in Australia (Compass; ACTRN12613001207707 and NCT02328872), which is conducted and funded by the VCS Foundation, a government-funded health promotion charity. KC's group at Cancer Council NSW, which included J-BL and $\mathrm{KS}$, performed modelling work on the transition from cytology-based screening to HPV-based screening, which was commissioned and funded by the Victorian Cytology Service. KC's group at Cancer Council NSW, which included J-BL and MC, performed modelling work to analyse the benefits, harms and cost-effectiveness of colorectal cancer screening. This work was auspiced by Cancer Council Australia and funded by the Australian Government Department of Health.

\section{Author contributions}

$\mathrm{J}-\mathrm{BL}$ lead the writing of the manuscript. $\mathrm{KC}$ conceived and oversaw the study. J-BL, SW, MC, Y-JK, CN, KS, and PP were responsible for data analysis. All authors participated in drafting the study, and reviewed and approved the final manuscript. 


\section{References}

1. Wilson J, Jungner G. Principles and practice of screening for disease. Geneva: World Health Organization; 1968 [cited 2019 Jun 27]. Available from: apps.who. int/iris/bitstream/handle/10665/37650/WHO_PHP_34. pdf? sequence $=17$

2. Lew JB, Simms K, Smith M, Kang YJ, Xu XM, Caruana M, et al. National Cervical Screening Program Renewal: effectiveness modelling and economic evaluation in the Australian setting. Report to the Medical Services Advisory Committee. Department of Health and Ageing. Australia; 2014.

3. National Health and Medical Research Council. How to compare the costs and benefits: evaluation of the economic evidence. Handbook series on preparing clinical practice guidelines. Canberra: Biotext; 2001.

4. Wang S, Gum D, Merlin T. Comparing the ICERs in Medicine Reimbursement Submissions to NICE and PBAC-Does the Presence of an Explicit Threshold Affect the ICER Proposed? Value Health. 2018;21(8):938-43.

5. Standing Committee on Screening. Population based screening framework (updated August 2018). Canberra: Australian Government Department of Health; 2018.

6. Nickson C, Velentzis LS, Brennan P, Mann GB, Houssami N. Improving breast cancer screening in Australia: a public health perspective. Public Health Res Pract. 2019;29(2):e2921911.

7. Roder D, Houssami N, Farshid G, Gill G, Luke C, Downey $P$, et al. Population screening and intensity of screening are associated with reduced breast cancer mortality: evidence of efficacy of mammography screening in Australia. Breast cancer research and treatment. 2008;108(3):409-16.

8. Nickson C, Mason KE, English DR, Kavanagh AM. Mammographic screening and breast cancer mortality: a case-control study and meta-analysis. Cancer Epidemiol Biomarkers Prev. 2012;21(9):1479-88.

9. BreastScreen Australia Evaluation Advisory Committee. Screening Monograph No. 9/2009 - Economic Evaluation and Modelling Study. Canberra: Department of Health and Ageing, Australian Government; 2009.

10. Elder K, Nickson C, Pattanasri M, Cooke S, Machalek D, Rose A, et al. Treatment intensity differences after earlystage nreast cancer (ESBC) diagnosis depending on participation in a screening program. Annals Surg Oncol. 2018;25(9):2563-72.

11. Cancer Australia. Overdiagnosis from mammographic screening. Position statement. Canberra: Cancer Australia; 2008 [cited 2019 Feb 22]. Available from: canceraustralia.gov.au/publications-and-resources/ position-statements/overdiagnosis-mammographicscreening

12. International Agency for Research on Cancer. Breast cancer screening. IARC handbooks of cancer prevention (Volume 7). Lyon, France: IARC; 2002.
13. Barratt AL, Les Irwig M, Glasziou PP, Salkeld GP, Houssami N. Benefits, harms and costs of screening mammography in women 70 years and over: a systematic review. Med J Aust. 2002;176(6):266-71.

14. Tuffaha HW, Mitchell A, Ward RL, Connelly L, Butler JRG, Norris S, Scuffham PA. Cost-effectiveness analysis of germ-line BRCA testing in women with breast cancer and cascade testing in family members of mutation carriers. Genet Med. 2018;20(9):985-94.

15. JNCI Monograph. The impact of mammography and adjuvant therapy on US breast cancer mortality (19752000): collective results from the Cancer Intervention and Surveillance Modeling Network. JNCI. 2006;2006(36).

16. Gray E, Donten A, Karssemeijer N, van Gils C, Evans DG, Astley S, Payne K. Evaluation of a stratified national breast screening program in the United Kingdom: an early model-based cost-effectiveness analysis. Value Health. 2017;20(8):1100-9.

17. Smith M, Canfell K. Impact of the Australian National Cervical Screening Program in women of different ages. Med J Aust. 2016;205(8):359-64.

18. Simonella L, Canfell K. The impact of a two-versus threeyearly cervical screening interval recommendation on cervical cancer incidence and mortality: an analysis of trends in Australia, New Zealand, and England. Cancer Causes \& Control. 2013;24(9):1727-36.

19. Australian institute of Health and Welfare. Cancer data in Australia Canberra: AlHW; 2018 [cited 2019 Feb 20]. Available from: www.aihw.gov.au/reports/cancer/cancerdata-in-australia/contents/summary

20. National HPV Vaccination Program Register. Coverage data. Canberra: National HPV Vaccination Program Register; 2019 [cited 2019 Mar 11]. Available from: http:// www.hpvregister.org.au/research/coverage-data

21. Brotherton JM, Tabrizi SN, Phillips S, Pyman J, Cornall AM, Lambie N, et al. Looking beyond human papillomavirus (HPV) genotype 16 and 18: defining HPV genotype distribution in cervical cancers in Australia prior to vaccination. Int J Cancer. 2017;141(8):1576-84.

22. Patel C, Brotherton JM, Pillsbury A, Jayasinghe S, Donovan B, Macartney K, Marshall $\mathrm{H}$. The impact of 10 years of human papillomavirus (HPV) vaccination in Australia: what additional disease burden will a nonavalent vaccine prevent? Euro Surveill. 2018;23(41).

23. Hall MT, Simms KT, Lew JB, Smith MA, Brotherton JM, Saville $\mathrm{M}$, et al. The projected timeframe until cervical cancer elimination in Australia: a modelling study. Lancet Public Health. 2019;4(1):e19-27.

24. Simms KT, Steinberg J, Caruana M, Smith MA, Lew JB, Soerjomataram I, et al. Impact of scaled up human papillomavirus vaccination and cervical screening and the potential for global elimination of cervical cancer in 181 countries, 2020-99: a modelling study. Lancet Oncol. 2019;20(3):394-407. 
25. Lew JB and Simms KT, Smith MA, Hall M, Kang YJ, Xu $\mathrm{XM}$, Caruana M, et al. Primary HPV testing versus cytology-based cervical screening in women in Australia vaccinated for HPV and unvaccinated: effectiveness and economic assessment for the National Cervical Screening Program. Lancet Public Health. 2017;2(2):e96-107.

26. Australian Government Department of Health. National Cervical Screening Program. Canberra: Commonwealth of Australia; 2018 [cited 2019 Jan 21] Available from: www.cancerscreening.gov.au/internet/screening/ publishing.nsf/Content/cervical-screening-1

27. Australian Institute of Health and Welfare. Cervical screening in Australia 2018. Canberra: AlHW; 2018 [cited 2019 Jul 19]. Available from: www.aihw.gov.au/ getmedia/8a26b34d-a912-4f01-b646-dc5d0ca54f03/aihwcan-111.pdf.aspx?inline $=$ true

28. National HPV Vaccination Program Register. Australia moves to two dose nine valent HPV vaccine in 2019. Canberra: National HPV Vaccination Program Register; 2019 [cited 2019 Jan 15]. Available from: http://www. hpvregister.org.au/health-professionals/announcements/ Australia\%20moves\%20to\%20two\%20dose\%20nine\%20 valent\%20HPV\%20vaccine\%20in\%2020181

29. Brotherton JML, Tabrizi SN, Phillips S, Pyman J, Cornall AM, Lambie N, et al. Looking beyond human papillomavirus (HPV) genotype 16 and 18: defining HPV genotype distribution in cervical cancers in Australia prior to vaccination. Int J Cancer. 2017;141(8):1576-84.

30. World Health Organisation. Cervical cancer elimination strategy. Geneva: WHO; 2019 [cited 2019 Jun 7]. Available from: www.who.int/cancer/cervical-cancer/ cervical-cancer-elimination-strategy

31. Simms KT, Smith MA, Lew JB, Kitchener HC, Castle PE, Canfell K. Will cervical screening remain cost-effective in women offered the next generation nonavalent HPV vaccine? Results for four developed countries. Int J Cancer. 2016;139(12):2771-80.

32. Australian Bureau of Statistics. Population projections, Australia, 2012 (base) to 2101. Canberra: Australian Bureau of Statistics; 2013 [cited 2019 Jul 4]. Available from: www.ausstats.abs.gov.au/ausstats/subscriber. nsf/0/13D196FB0DBECC3BCA257C2E00173FAD/\$Fi le/32220_2012\%20(base)\%20to\%202101.pdf

33. Australian Institute of Health and Welfare. BreastScreen Australia monitoring report 2018. Canberra: AlHW; 2018 [cited 2019 Jul 4]. Available from: www.aihw.gov.au/ getmedia/c28cd408-de89-454f-9dd0-ee99e9163567/ aihw-can-116.pdf.aspx?inline=true

34. Lew JB, St John DJB, Macrae FA, Emery JD, Ee HC, Jenkins MA, et al. Benefits, harms and cost-effectiveness of potential age-extensions to the National Bowel Cancer Screening Program in Australia. Cancer Epidemiol Biomarkers Prev. 2018;27(12):1450-1461.
35. Wade S, Weber M, Caruana M, Kang YJ, Marshall $H$, Manser R, et al. Estimating the cost-effectiveness of lung cancer screening with low-dose computed tomography for high-risk smokers in Australia. J Thorac Oncol. 2018;13(8):1094-105.

36. Australian Bureau of Statistics. Consumer Price Index, Australia, Mar 2019. Canberra: ABS; 2019 [cited 2019 Jul 4]. Available from: www.ausstats.abs.gov.au/ausstats/ meisubs.nsf/0/ABD6A269C03FB4A0CA2583E5001D67B A/\$File/64010_mar\%202019.pdf

37. Hall MT, Simms KT, Lew JB, Smith MA, Saville M, Canfell K. Projected future impact of HPV vaccination and primary HPV screening on cervical cancer rates from 2017-2035: example from Australia. PloS one. 2018;13(2):e0185332.

38. Lew JB, St John DJB, Macrae FA, Emery JD, Ee HC, Jenkins MA, et al. Evaluation of the benefits, harms and cost-effectiveness of potential alternatives to iFOBT testing for colorectal cancer screening in Australia. Int J Cancer. 2018;143(2):269-82.

39. Lew JB, St John DJB, Xu XM, Greuter MJE, Caruana M, Cenin DR, et al. Long-term evaluation of benefits, harms, and cost-effectiveness of the National Bowel Cancer Screening Program in Australia: a modelling study. Lancet Public Health. 2017;2(7):e331-40.

40. Aberle DR, Adams AM, Berg CD, Black WC, Clapp JD, Fagerstrom RM, et al. Reduced lung-cancer mortality with low-dose computed tomographic screening. N Engl J Med. 2011;365(5):395-409.

41. Ee HC, St John J. The National Bowel Cancer Screening Program: time to achieve its potential to save lives. Public Health Res Pract. 2019;29(2):e2921915.

42. Australian Institute of Health and Welfare. National Bowel Cancer Screening Program monitoring report 2018. Canberra: AlHW; 2018 [cited 30 Jul 19]. Available from: www.aihw.gov.au/getmedia/df120b1a-1bda-49c1-861117a7256e61d0/aihw-can-12.pdf.aspx?inline=true

43. Feletto E, Yu XQ, Lew JB, St John DJB, Jenkins MA, Macrae FA, et al. Trends in colon and rectal cancer incidence in Australia from 1982 to 2014: analysis of data on over 375,000 cases. Cancer Epidemiol Biomarkers Prev. 2019;28(1):83-90.

44. Department of Human Service. Requested Medicare items processed from July 2017 to June 2018. Canberra: Commonwealth of Australia; 2019 [cited 2019 Mar 8]. Available from: medicarestatistics.humanservices.gov. au/statistics/do.jsp?_PROGRAM=\%2Fstatistics\%2Fmbs_ item_standard_report\&DRILL=ag\&group $=66655 \% 2 \mathrm{C} 666$ $56 \& V A R=$ services $\& S T A T=$ count\&RPT_FMT $=$ by + state \&PT YPE=finyear\&START_DT=201707\&END_DT =201806

45. Schroder FH, Hugosson J, Roobol MJ, Tammela TL, Ciatto S, Nelen V, et al. Prostate-cancer mortality at 11 years of follow-up. N Engl J Med. 2012;366(11):981-90. 
46. Andriole GL, Crawford ED, Grubb RL 3rd, Buys SS, Chia D, Church TR, et al. Prostate cancer screening in the randomized Prostate, Lung, Colorectal, and Ovarian Cancer Screening Trial: mortality results after 13 years of follow-up. J Natl Cancer Inst. 2012;104(2):12532.

47. Ilic D, Djulbegovic M, Jung JH, Hwang EC, Zhou Q, Cleves A, et al. Prostate cancer screening with prostatespecific antigen (PSA) test: a systematic review and meta-analysis. BMJ. 2018;362:k3519.

48. Prostate Cancer Foundation of Australia and Cancer Council Australia PSA Testing Guidelines Expert Advisory Panel. Draft clinical practice guidelines for PSA testing and early management of test-detected prostate cancer. Sydney: Prostate Cancer Foundation of Australia and Cancer Council Australia; 2016.

49. Martin AJ, Lord SJ, Verry HE, Stockler MR, Emery JD. Risk assessment to guide prostate cancer screening decisions: a cost-effectiveness analysis. Med J Aust. 2013;198(10):546-50.

50. Cancer Council NSW. Policy1: Policy1-Prostate 2019. Sydney: Cancer Council NSW; 2019 [cited 2019 Jun 9]. Available from: www.policy1.org/models/prostate

51. Weber MF, Marshall HM, Rankin N, Duffy S, Fong KW. Opportunities for lung cancer screening in Australia. In: Cancer screening in Australia: future directions in melanoma, Lynch syndrome, and liver, lung and prostate cancers. Public Health Res Pract. 2019;29(2):e2921910.

52. Brims F, McWilliams A, Fong K. Lung cancer screening in Australia: progress or procrastination? Med J Aust. 2016;204(1):4-5.

53. National Lung Screening Trial Research Team. The National Lung Screening Trial: overview and study design. Radiology. 2011;258(1):243-53.

54. Snowsill TM, Yang H, Griffin E, Long HL, Varley-Campbell J, Coelho H, et al. Low-dose computed tomography for lung cancer screening in high risk populations: a systematic review and economic evaluation. Health Technol Assess. 2018;22(69):1-276.
55. National Institutes of Health, US National Library of Medicine: ClinicalTrials.gov. Bethesda, MD: NIH NLM; 2019. International Lung Screen Trial (ILST) (NCT02781856); 2016 [cited 2019 Jun 11]; [about 4 screens]. Available from: clinicaltrials.gov/ct2/show/NCT0 2871856? id =NCT02871856\&rank $=1$

56. Taylor N, Mitchell G, Kang Y-J, Tucker K, Jenkins M, Macrae F. Opportunities for Lynch syndrome testing. In: Cancer screening in Australia: future directions in melanoma, Lynch syndrome, and liver, lung and prostate cancers. Public Health Res Pract. 2019;29(2):e2921910.

57. Medical Services Advisory Committee. Public summary document: applications no. 1504 - heritable mutations which increase risk in colorectal and endometrial cancer 2018. Canberra: Australian Government Department of Health [cited 2019 Feb 20]. Available from: msac.gov.au/ internet/msac/publishing.nsf/Content/1504-public

58. Breheny N, Geelhoed E, Goldblatt J, Ee H, O'Leary P. Economic evaluation of the familial cancer programme in Western Australia: predictive genetic testing for familial adenomatous polyposis and hereditary nonpolyposis colorectal carcinoma. Community genetics. 2006;9(2):98-106.

59. Ananda S, Kosmider S, Tran B, Field K, Jones I, Skinner I, et al. The rapidly escalating cost of treating colorectal cancer in Australia. Asia Pac J Clin Oncol. 2016;12(1):33-40.

60. Cenin DR, Naber SK, Lansdorp-Vogelaar I, Jenkins MA, Buchanan DD, Preen DB, et al. Costs and outcomes of Lynch syndrome screening in the Australian colorectal cancer population. J Gastroenterol Hepatol. 2018;33(10):1737-44.

61. Kang YJ, Killen J, Caruana M, Simms K, Taylor N, Frayling IM. The effectiveness and the cost-effectiveness of systematic testing for Lynch syndrome in incident colorectal cancer cases in Australia. Forthcoming 2019.

\section{Copyright: (c) (i) (2)}

(c) 2019 Lew et al. This article is licensed under the Creative Commons Attribution-NonCommercial-ShareAlike 4.0 International Licence, which allows others to redistribute, adapt and share this work non-commercially provided they attribute the work and any adapted version of it is distributed under the same Creative Commons licence terms. See: www.creativecommons.org/licenses/by-nc-sa/4.0/ 